LICENÇA CC BY: Artigo distribuído sob os termos Creative Commons, permite uso e distribuição irrestrita em qualquer meio desde que o autor credite a fonte original.

\title{
VITALISMO FILOSÓFICO EM NIETZSCHE: FUNDAMENTOS EPISTEMOLÓGICOS E A VALORIZAÇÃO DA ARTE NA EDUCAÇÃO
}

\author{
NIETZSCHE'S PHILOSOPHICAL VITALISM: EPISTEMOLOGICAL \\ FOUNDATIONS AND THE APPRECIATION OF ART IN EDUCATION \\ VITALISMO FILOSÓFICO EN NIETZSCHE: FUNDAMENTOS \\ EPISTEMOLÓGICOS Y LA VALORIZACIÓN DEL ARTE EN LA \\ EDUCACIÓN
}

Fabio Hecktheuer ${ }^{1}$ Lenir Lopes ${ }^{2}$ Josenir Lopes Dettoni

${ }^{1}$ Faculdade Católica de Rondônia, Porto Velho, RO, Brasil. 2Universidade Federal de Rondônia, Porto Velho, RO, Brasil.

Artigo recebido em: 01/10/2020

Aprovado em: 03/11/2020

Resumo: Esta pesquisa busca responder à questão da possível relação entre o posicionamento epistemológico de Nietzsche e o papel da Arte na Educação. Para isso, estudamos os fundamentos epistemológicos da filosofia nietzscheana, em especial a temática relativa à verdade, à crítica à supervalorização da razão e a uma sabedoria a serviço da vida. Em seguida, examinamos as consequências educacionais de um pensamento vitalista. Metodologicamente, realizamos pesquisa bibliográfica, investigando relevantes obras de Nietzche sobre o tema, bem como de comentadores de sua filosofia. Na composição do texto, organizamos seis seções: Introdução; A questão da verdade em Nietzsche; Filosofia tradicional e supervalorização da razão; Uma filosofia a serviço da vida; Implicações Educacionais; e Considerações Finais. Com a pesquisa, pudemos concluir que a Arte tem papel essencial na Educação, inspirada no vitalismo nietzschiano, o que nos interpela acerca do lugar que como sociedade temos dado à dimensão estética no âmbito educacional contemporâneo.

Palavras-chave: Nietzsche; Epistemologia; Filosofia da Educação; Educação; Estética.

Abstract: This research seeks to answer the question of the possible relationship between Nietzsche's epistemological positioning and the role of Art in Education. For this, we study the epistemological foundations of Nietzschean philosophy, in particular the theme of truth, the critique of the overvaluation of reason and a wisdom in the service of life. We then examine the educational consequences of vitalist thinking. In 
terms of methodology, we conducted bibliographic research, investigating relevant works by Nietzsche on the subject, as well as commentators of his philosophy. The text was composed in six sections: Introduction; The Question of Truth in Nietzsche; Traditional philosophy and overvaluation of reason; A philosophy in the service of life; Educational implications; and Final Considerations. Based on this research, we conclude that Art plays an essential role in Education inspired by Nietzschean vitalism, which challenges us about the place that we, as a society, have given to the aesthetic dimension in the scope of contemporary education.

Keywords: Nietzsche; Epistemology; Philosophy of education; Education; Aesthetics.

Resumen: Esta investigación busca responder la cuestión de la posible relación entre la posición epistemológica de Nietzsche y el papel del Arte en la Educación. Para eso, estudiamos los fundamentos epistemológicos de la filosofía nietzscheana, en especial la temática relativa a la verdad, a la crítica, a la supervalorización de la razón y a una sabiduría al servicio de la vida. En seguida, examinamos las consecuencias educacionales de un pensamiento vitalista. Metodológicamente, realizamos investigación bibliográfica, investigando relevantes obras de Nietzche sobre el tema, bien como de comentadores de su filosofía. En la composición del texto, organizamos seis secciones: Introducción; La cuestión de la verdad en Nietzsche; Filosofía tradicional y supervalorización de la razón; Una filosofía al servicio de la vida; Implicaciones Educacionales; y Consideraciones Finales. Con la investigación, podemos concluir que el Arte tiene papel esencial en la Educación, inspirada en el vitalismo nietzschiano, lo que nos interpela sobre el lugar como sociedad hemos dado a la dimensión estética en el ámbito educacional contemporáneo.

Palabras clave: Nietzsche; Epistemología; Filosofía de la Educación; Educación; Estética.

\section{Introdução:}

A busca pela verdade é empreendida pela humanidade desde suas origens. O campo teórico que investiga as condições dessa busca é a Epistemologia, também definida como teoria do conhecimento. Um importante filósofo desse campo, particularmente por sua impactante influência no pensamento contemporâneo, é Friedrich Wilhelm Nietzsche (1844 1900). Este pesquisa busca responder à questão da possível relação entre seu posicionamento epistemológico e o papel da Arte na Educação.

Desse modo, o problema de nosso estudo, que se situa na área da Filosofia da Educação, está assim formulado: o posicionamento epistemológico de Nietzsche pode contribuir para a valorização da arte no âmbito educacional? Para tanto, buscaremos entender os fundamentos de sua Epistemologia, em especial quanto à temática relativa à verdade, à crítica à supervalorização da razão e a uma sabedoria a serviço da vida. Ato contínuo, analisaremos uma relevante consequência de seu pensamento, denominado vitalismo, para a Educação contemporânea: o valor da arte para a formação humana.

Metodologicamente, realizamos pesquisa bibliográfica, investigando relevantes obras de Nietzsche sobre o tema, bem como alguns dos seus comentadores de sua filosofia. $\mathrm{Na}$ estruturação do texto, organizamos seis seções: Introdução; A questão da verdade em Nietzsche; Filosofia tradicional e supervalorização da razão; Uma filosofia a serviço da vida; Implicações Educacionais; e Considerações Finais. 


\section{A questão da verdade em Nietzsche:}

Na elaboração de todo e qualquer trabalho filosófico parece existir, como compromisso de amor à sabedoria, um esforço de aproximação da verdade. É como se ambas, sabedoria e verdade, estivessem tão intimamente unidas que a validade do conhecimento humano seria definitivamente comprometida caso se separassem. Em outras palavras, filosofar para se amar a sabedoria como expressão racional da verdade.

Contudo, Nietzsche, com seu pensamento incisivo e profundamente heterodoxo, questiona não só a concepção de sabedoria de sua época, como também a própria verdade, classificando o conhecimento humano como metáfora ou ilusão.

Neste ponto, faz-se sentir, apesar da imensa distância filosófica que os separa, a influência do pensamento de Kant sobre Nietzsche. O "filósofo do martelo", ao desconstruir o conceito de verdade, afirma que "a 'a coisa em si' (tal seria justamente a verdade pura sem consequências) é, também para o formador da linguagem, inteiramente incaptável e nem sequer algo que vale a pena. Ele designa apenas as relações das coisas aos homens e toma em auxílio para exprimi-las as mais audaciosas metáforas" (NIETZSCHE, 1974f, p. 55). Deste modo, a linguagem não serve para designar a verdade, tendo, contudo, outra função.

Seguindo passos darwinistas, Nietzsche apresenta tal função afirmando que "o intelecto, como um meio para a conservação do indivíduo, desdobra suas forças mestras no disfarce; pois este é o meio pelo qual os indivíduos mais fracos, menos robustos, se conservam, aqueles aos quais está vedado travar uma luta pela existência com chifres ou presas aguçadas" (NIETZSCHE, $1974 f$, p. 53). Assim, o intelecto, a razão e a linguagem são vistos não como instrumentos humanos a serviço da verdade, mas sim a serviço da vida, da sobrevivência.

Tal concepção nos leva novamente à pergunta da relação entre conhecimento, entendido como sabedoria, e verdade. Aqui, Nietzsche é enfático:

O que é a verdade, portanto? Um batalhão móvel de metáforas, metonímias, antropomorfismos, enfim, uma soma de relações humanas, que foram enfatizadas poética e retoricamente, transpostas, enfeitadas, e que, após longo uso, parecem a um povo sólidas, canônicas e obrigatórias: as verdades são ilusões, das quais se esqueceu que o são, metáforas que se tornaram gastas e sem força sensível, moedas que perderam um efígie e agora só entram em consideração como metal, não mais como moedas. (NIETZSCHE, 1974f, p. 56).

Assim, a verdade é vista como filha da mentira e do esquecimento; uma filha que, ao longo do processo civilizatório, foi elevada às alturas e divinizada.

(...) Também nós, conhecedores de hoje, nós os sem-Deus e os antimetafísicos, também nosso fogo, nós o tiramos ainda da fogueira que uma crença milenar acendeu, aquela crença cristã, que era também a crença de Platão, de que Deus é a verdade, de que a verdade é divina... Mas, e se precisamente isso se tornar cada vez mais desacreditado, se nada mais se demonstrar como divino, que não seja o erro, a cegueira, a mentira - se Deus mesmo se demonstrar como nossa mais longa mentira? (NIETZSCHE, 1974a, p. 221).

Essa hipótese epistemológica de Nietzsche descortina uma importante reflexão sobre a Filosofia tradicional em contraposição a uma proposta que valorize a vida. 


\section{Filosofia tradicional e supervalorização da razão:}

Com a divinização da verdade, nasceu na cultura ocidental uma supervalorização da razão. Essa passou a ser vista, no início da filosofia clássica, como o caminho a ser trilhado para se alcançar a felicidade. Sem o conhecimento do logos, sem o pensar filosófico, o homem chegou a ser descrito, na famosa Alegoria da Caverna de Platão, como um cativo, preso a pesados grilhões, que vivia nas trevas e tinha como visão de mundo sombras distorcidas de uma realidade que não podia enxergar.

Contudo, Nietzsche (1974f, p.53) não poupa críticas a esse posicionamento e chega denominar o filósofo como o mais orgulhoso dos homens. Orgulhoso por sua presunção de conhecer a realidade. Orgulhoso e vaidoso. Vaidoso e mentiroso, já que a própria verdade não passa de mentira, ilusão, antropomorfismo; mesmo que disso o filósofo não tenha consciência.

Ora, essa presunção do filósofo, fruto da supervalorização da razão, não é incólume à cultura e à vida como a vivemos. Ela acarreta sérios prejuízos para os homens. Tal qual célula cancerígena que se reproduz em demasia, quando se dá à razão um espaço maior do que deveria ter em nossa vida, ela acaba por prejudicá-la e até destruí-la. O intelecto, que deveria servir para conservar a vida, passa a desvalorizá-la e negá-la.

Scarlett Marton, estudiosa nietzscheana, descreve bem como se deu esse processo:

Diante do espetáculo da própria finitude, o homem inventou o pensar metafísico e a religião cristã. E tudo fez para livrar-se da visão do sofrimento imposto pela morte. Mas alto foi o preço a pagar: teve de negar este mundo, teve de condenar esta vida. Com o pensar metafísico, tentou impor a existência de outro mundo, de um mundo verdadeiro, imutável. Com a religião cristã, buscou forjar a existência de outra vida, de uma vida melhor, mais feliz, eterna. (MARTON, 2000, p. 46).

É nesse sentido que Nietzsche adverte:

Fabular sobre um 'outro' mundo, que não este, não tem nenhum sentido, pressuposto que um instinto de calúnia, apequenamento, suspeição contra a vida, não tem potência em nós: neste último caso vingamo-nos da vida com a fantasmagoria de uma 'outra' vida, de uma vida 'melhor'. (NIETZSCHE, 1974b, p.340).

Assim, para suportar a transitoriedade de sua existência, o homem valeu-se da negação da morte como mecanismo de defesa. Para isso, teve que criar para si, por meio de racionalizações, a ilusão de uma vida perene, seja num mundo filosófico, metafísico, seja num mundo espiritual, religioso. Como parte desse mecanismo, passou a projetar sua felicidade para fora desta vida, acarretando a desvalorização de aqui e agora. É essa desvalorização, presente de maneira intrínseca na religião e na filosofia tradicional, que Nietzsche condena e chama de calúnia e apequenamento. Apequenamento porque tira valor da vida e porque quer reduzir à razão toda a existência. "São somente os homens demasiado ingênuos que podem acreditar que a natureza do homem possa ser transformada em uma natureza lógica (...)!" (NIETZSCHE, 1974d, p.104).

Ora, aqui cabe uma importante indagação acerca da presente reflexão: diante da negação da verdade e da dura crítica nietzscheana à filosofia tradicional, como é possível 
elaborar qualquer trabalho filosófico, defender qualquer posicionamento sobre o pensamento de Nietzsche, sem incorrer em uma contradição performática? A resposta parece encontrar-se nas bases de uma nova filosofia apresentada por Nietzsche.

\section{Uma filosofia a serviço da vida:}

Com espírito aguçado, Nietzsche assume uma postura crítica com relação à Filosofia e questiona a tradicional oposição entre razão e paixões. Para ele, o papel do filósofo está em analisar se uma suposta verdade filosófica está ou não a serviço da vida, se contribui para seu revigoramento ou decadência (MARTON, 1983, p. 24).

A partir dessa postura, Nietzsche é capaz, inclusive, de defender o espaço do ilógico dentro da filosofia, se isso servir para fortalecer a vida. Ele sabe, contudo, que tal posicionamento escandaliza a muitos e pode acarretar confusão e até desespero: "Entre as coisas que podem levar um pensamento ao desespero está o conhecimento de que o ilógico é necessário para o homem e de que do ilógico nasce muito de bom" (NIETZSCHE, 1974d, p.104). O ilógico está muito presente nas paixões, na linguagem, na religião e em geral em várias manifestações que buscam valorizar a vida. Tentar extirpá-lo, seguindo uma supervalorização do racional, equivaleria a arruiná-las.

Com isso, Nietzsche defende claramente o direito ao contrassenso, na filosofia e na vida; e talvez por isso muitas pessoas sustentem que ele não pode ser considerado um filósofo, mas apenas um literato. Nietzsche se defende:

\footnotetext{
A falsidade de um juízo não pode constituir, em nossa opinião, uma objeção contra esse juízo. Esta poderia ser uma das afirmativas mais surpreendentes de nossa linguagem. A questão é saber em que medida este juízo serve para conservar a espécie, para acelerar, enriquecer e manter a vida. Por princípio estamos dispostos a sustentar que os juízos mais falsos (...) são para nós mais indispensáveis, que o homem não poderia viver sem as ficções da lógica, sem o relacionar a realidade com a medida do mundo puramente imaginário do incondicionado e sem falsear constantemente o mundo através do número; renunciar aos juízos falsos equivaleria a renunciar à vida, a renegar à vida. Admitir que o não-verdadeiro é a condição da vida, é opor-se audazmente ao sentimento que se tem habitualmente dos valores. Uma filosofia que se permita tal intrepidez se coloca, apenas por este fato, além do bem e do mal. (NIETZSCHE, s/d., p.21-22).
}

Essa nova filosofia a serviço da vida, que admite inclusive o não verdadeiro, o ilógico e a ficção, aproxima-se muito, por essas mesmas características, da manifestação artística.

Com sua peculiar concepção filosófica, Nietzsche vê no conhecimento uma forma de ilusão e aponta para a arte como fator privilegiado de relação entre o mundo e o homem. "A arte é essencialmente dizer-sim, abençoar, divinizar a existência (...)" (NIETZSCHE, In: MARTON, 1983, p. 44). Encantado com o papel da arte, Nietzsche (1974g, p. 36) chega a afirmar: "(...) a arte tem mais valor do que a verdade". É desse modo que a arte e a filosofia se relacionam na obra de Nietzsche. A realidade a ser descrita pela filosofia não está dada, precisa ser criada e recriada constantemente. Não se trata mais de descobrir a verdade e dogmatizá-la. A tarefa da filosofia agora, assim como a da arte, é embelezar a vida, afirmá-la. 
Contudo, tal embelezamento não significa negação do sofrimento. Afirmar a vida significa assumir a existência em todos os seus aspectos. Assim, para Nietzsche (1974c, p.374), a filosofia significa, antes de mais nada, vivência:

Filosofia, tal como até agora a entendi e vivi, é a vida voluntária em gelo e altas montanhas - a procura por tudo o que é estrangeiro e problemático na existência, por tudo aquilo que até agora foi exilado pela moral. [...] De uma longa experiência que me foi dada por tal andança pelo proibido, aprendi a considerar as causas pelas quais até agora se moralizou e idealizou, de modo muito diferente do que seria desejável: a história escondida dos filósofos, a psicologia de seus grandes nomes, veio à luz para mim.

Nietzsche, assim, ao aproximar a filosofia e a vida, aproxima o pensamento dos filósofos de sua história subjacente: a psicologia parece, então, entrar em cena. Mais uma vez, a razão e as paixões humanas se mesclam; e a filosofia se nutre da experimentação de diversos estados de espírito.

Uma filosofia experimental, tal como eu a vivo, antecipa experimentalmente até mesmo as possibilidades do niilismo radical; sem querer dizer com isso que ela se detenha em uma negação, no não, em uma vontade de não. Ela quer, em vez disso, atravessar até ao inverso - até a um dionisíaco dizer-sim ao mundo, tal como é, sem desconto, exceção e seleção (...). Supremo estado que um filósofo pode alcançar: estar dionisiacamente diante da existência - minha fórmula para isso é amor fati. (NIETZSCHE, 1974e, p. 401).

O amor à existência tal qual ela se apresenta: com alegrias e sofrimentos, com dúvidas e certezas. Para que isso se dê, o próprio pensamento precisa aceitar a contradição: "Serão amigos da 'verdade' esses filósofos do amanhã? Possivelmente, pois todos os filósofos foram amigos das suas verdades. Mas, não serão certamente, pensadores dogmáticos" (NIETZSCHE, s/d., p. 56). Porque já não cabe, dentro dessa nova concepção filosófica, a defesa de uma verdade absoluta.

Ora, aqui mais uma vez se apresenta a crítica da contradição performática: como é possível falar verdadeiramente que a verdade não existe?

A resposta parece ser que Nietzsche, com todo seu pensamento, não se apresenta como verdadeiro, não quer falar verdadeiramente. Não quer e não faz, pois, como já vimos, denuncia qualquer pretensão de verdade e, inclusive, defende o ilógico como fundamental para a existência. Em outras palavras, quem insistir em defender a existência de uma verdade suprema, universal e imutável, permanecerá se debatendo diante dessa contradição; quem contudo se colocar fora dessa lógica e perceber que a verdade é uma construção social, fruto da coletivização de diversas perspectivas individuais, não terá problema algum com ela.

Eis o perspectivismo, que Nietzsche (1974d, p. 97) aqui recomenda com as seguintes palavras: "Devias aprender a conceber o perspectivístico de toda estimativa de valor - o deslocamento, a distorção e teleologia aparente dos horizontes e de tudo aquilo que pertence ao perspectivístico [...]".

Temos, assim, os fundamentos epistemológicos da filosofia nietzscheana, denominada vitalista por defender uma sabedoria a serviço da vida. 


\section{Implicações Educacionais:}

Do posicionamento epistemológico de Nietzsche, em especial de sua condenação a uma cultura que supervaloriza a racionalidade em detrimento do fortalecimento da vida, deriva um posicionamento educacional que critica a pedagogia moderna por estar preso a um ensino abstrato e histórico que distancia o saber da vida e que oferece uma formação apenas para fazer do homem um ser útil ao trabalho.

Com efeito, desde uma perspectiva nietzschiana,

A crítica à educação moderna encontra-se na pretensão do Estado e das instituições de ensino em fazer do homem um ser utilitário, este pronto para lhe servir em todos os níveis sociais e institucionais. Ambos instruem os jovens para o mercado de trabalho com um conhecimento mínimo de cultura. Educação, para o Estado e instituições de ensino, não passa de instrução para o mercado, meio de se alcançar um emprego e um salário para o consumo. (OLIVEIRA, 2014, p. 93).

Por ser padronizado, único para todos, e por reservar ao homem o destino de escravo do trabalho e do consumo, o modelo de educação dos estabelecimentos de ensino é criticado por oferecer "uma educação fomentadora da mediocridade em todos os âmbitos da sociedade" (OLIVEIRA, 2014, p. 96), sendo considerado como enfraquecedor da vida.

Ora, em contrapartida,

Embora não seja possível encontrarmos uma construção teórica educacional sistematizada nos escritos do jovem Nietzsche, a contribuição do filósofo, assim entendemos, está em considerar como melhor modelo de educação a junção da vida e da arte. O melhor modelo de educação é o que estabelece uma relação direta entre a vida e arte. Essa relação promove a vida e a cultura. $\mathrm{Na}$ educação e cultura moderna a arte é suprimida, critica Nietzsche. (OLIVEIRA, 2014, p. 93).

Assim, o ensino moderno, segundo o pensador, fragiliza a vida e a adoece. Em contrapartida, "a educação defendida por Nietzsche articula a arte com o saber e o saber com a vida. Para isso, as habilidades a serem desenvolvidas nos jovens pela educação são aprender a pensar, a lidar com conceitos e palavras, dominar a escrita e desenvolver a criatividade artística" (OLIVEIRA, 2014, p. 93). Desse modo, a proposta educacional de Nietzsche preconiza a relação do homem com a vida, sobretudo por meio do auxílio da Filosofia e da Arte. Para esse filósofo, em contraposição a uma tendência racionalista moderna,

O sujeito da educação é o corpo porque é nele que está a vida. É o corpo que quer aprender para poder viver. É ele que dá as ordens. A inteligência é um instrumento do corpo cuja função é ajudá-lo a viver. Nietzsche dizia que ela, a inteligência, era "ferramenta" e "brinquedo" do corpo. Nisso se resume o programa educacional do corpo: aprender "ferramentas", aprender "brinquedos". "Ferramentas" são conhecimentos que nos permitem resolver os problemas vitais do dia a dia. "Brinquedos" são todas aquelas coisas que, não tendo nenhuma utilidade como ferramentas, dão prazer e alegria à alma. [...] Nessas duas palavras, ferramentas e brinquedos, estão o resumo de educação. [...] Assim todo professor, ao ensinar, teria que perguntar: "Isso que vou ensinar, é ferramenta? É brinquedo?" Se não for é melhor deixar de lado. (ALVES, 2001, p. 02).

Também quanto à finalidade da Educação, Nietzsche é propositivo. Ele apregoa uma formação que prepare o homem para o cultivo de si mesmo, capacitando-o, pela arte e filosofia, para conduzir a vida com heroísmo, a fim de torná-la única. 
No pensamento educacional do jovem Nietzsche, portanto, educação é direcionar o homem para a produção da cultura que surge na consideração da vida como sendo um eterno processo de formação de si mesmo. Para conseguir o cultivo de si mesmo, ele deve se aproximar dos homens que fizeram da vida uma obra de arte com inventividade e habilidade no pensar artístico; deve imaginar exemplos heroicos das obras de arte, viver e aceitar toda dor que vier da vida. A vida vale a pena quando se é pensada para ser vivida com arte! (OLIVEIRA, 2014, p. 96).

A Educação deve ensinar o sujeito a inspirar-se nos modelos de grandes homens que heroicamente fizeram da vida uma obra de arte. "É por isso que a arte surge como elemento essencial na educação pensada por Nietzsche. Essa educação é marcada pela valorização da sensibilidade e da experiência estética" (OLIVEIRA, 2014, p. 93). Só o cultivo da arte pode preparar esse dionisíaco amor fati, essa atitude estética de aceitação integral da vida, que o homem deve ter.

Portanto, é possível constatarmos que,

A arte, nos seus múltiplos conceitos e definições, é inspiração permanente no pensamento educacional de Nietzsche em vários sentidos. Ela educa o homem em sentido mais amplo do que a educação escolar, simplesmente porque a vida é reconhecida, experimentada e justificada como fenômeno estético. (OLIVEIRA, 2014, p. 93).

Um vitalismo educacional, assim, certamente atribui à arte, à dimensão estética, um lugar de destaque no processo de formação para o cultivo de si mesmo. A arte é intrínseca e amplamente valorizada nessa perspectiva educacional. Sem arte, em suma, não podemos pensar em uma Educação que seja boa para a vida.

\section{Considerações Finais:}

Ao longo desse artigo, buscamos investigar a relação entre a Epistemologia de Nietzsche e a reflexão sobre o papel que a Arte deve desempenhar na Educação. O autor escolhido, embora polêmico, e em alguns pontos até controverso, apresenta uma contundente e importante crítica aos paradigmas medieval e moderno acerca dessa temática, influenciando decisivamente os rumos do pensamento contemporâneo.

A fim de atingirmos esse objetivo, após a Introdução, passamos a examinaros fundamentos epistemológicos da filosofia nietzschiana. Na segunda seção do trabalho, pudemos observar como o autor é incisivo ao classificar a verdade como metonímia, antropomorfismo, metáfora ou ilusão, destituindo-a de sua centralidade teórica. Esse lugar passa a ser ocupado pela busca do fortalecimento da vida.

Tal contraposição pôde ser mais bem aprofundada nas seções terceira e quarta, em que apresentamos como Nietzsche avalia a Filosofia tradicional, para ele supervalorizadora da razão; e sua proposta de uma nova Filosofia a serviço da vida, em que até o ilógico e a ficção poderiam ser admitidos. Aqui, a Arte recebe grande reconhecimento como promotora de valorização da existência, ganhando lugar de destaque em sua teoria, sendo considerada até como mais importante que a própria verdade. 
Em seguida, na quinta seção, examinamos como esse pensamento vitalista pode acarretar consequências para a discussão do lugar da Arte no âmbito educacional. Com efeito, ao questionar o papel da racionalidade e o próprio estatuto do que consideramos como verdade, Nietzsche abre um importante espaço para a valorização da Arte na Educação. É a Epistemologia apontando para a Estética como caminho formativo para uma humanidade comprometida com o fortalecimento da vida.

Por fim, importa salientar que o pensamento de Nietzsche sobre o destacado papel da Arte na Educação nos interpela, fazendo-nos questionar se estamos dando à formação estética o justo e importante lugar que ela deve ter em um processo educacional que sirva à vida.

\section{Referências}

ALVES, R. Gaiolas ou asas. Folha de São Paulo, São Paulo, 05 dez de 2001. Tendências e debates. Disponível em: < https://www1.folha.uol.com.br/fsp/opiniao/fz0512200109.htm>. Acesso em: $17 / 12 / 19$.

MARTON, Scarlett. Extravagâncias: ensaios sobre a filosofia de Nietzsche. São Paulo: Discurso Editorial e Ed. UNIJUÍ, 2000. p. 46.

Friedrich Nietzsche: uma filosofia a marteladas. São Paulo: Brasiliense, 1983.

NIETZSCHE, Friedrich. A Gaia Ciência. São Paulo: Abril Cultural, 1974a.

Além do Bem e do Mal. Rio de Janeiro: Ediouro, s/d.

Crepúsculo dos Ídolos. São Paulo: Abril Cultural,1974b.

Ecce Homo. São Paulo: Abril Cultural, 1974c.

Humano, demasiado Humano. São Paulo: Abril Cultural,1974d.

Ensaio sobre o Niilismo e o Eterno Retorno. São Paulo: Abril Cultural, 1974e.

Sobre Verdade e Mentira no Sentido Extra-Moral. São Paulo: Abril Cultural, $1974 f$.

O Nascimento da Tragédia no Espírito da Música. São Paulo: Abril Cultural, 1974g.

OLIVEIRA, José Airton Araújo de. Educação, Arte e Vida no Pensamento do Jovem Nietzsche.

Dissertação (Mestrado em Filosofia) - Programa de Pós-Graduação em Filosofia, Universidade Federal do Rio Grande do Norte. Natal: 2014. 